\title{
PITOT 管流量計によるエンジン脈動流計測の解析*
}

\author{
中 村 博 司*1, 浅 野 一 朗*2 \\ 足立 正 之*1, 千田二 郎*3
}

\section{Analysis of Pulsating Flow Measurement of Engine Exhaust by Pitot Tube Flow Meter}

\author{
Hiroshi NAKAMURA*4, Ichiro ASANO, \\ Masayuki ADACHI and Jiro SENDA \\ ${ }^{* 4}$ HORIBA, Ltd., Emission Analysis R \& D Dept., \\ 2 Miyanohigashi, Kisshoin, Minami-ku, Kyoto-shi, Kyoto, 601-8510 Japan
}

\begin{abstract}
Pitot tube flow metering technique has been used to measure pulsating flow from a vehicles engine exhaust. In general, flow metering techniques that utilize differential pressure measurements based on the Bernoulli's theory likely to show erroneous reading when measuring an average flow rate of pulsating flow. The primary reason for this is the non-linear relationship between the differential pressure and the flow rate, i.e. the flow rate is proportional to the square root of the differential pressure. Thus, an average of the differential pressure does not give an average of pulsating flow. In the present study, fast response pressure transducers have been used to measure the pulsating pressure as raw as possible. Then, the pulsating differential pressure is converted to flow rate keeping the pulsation not averaged. An average of the flow rate is then calculated in flow rate domain in order to maintain the linearity of before and after the averaging. The peak amplitude of a pulsation measured here was about $1800 \mathrm{LPM}$ at the average flow rate of $70 \mathrm{LPM}$ when an engine was idling. This measurement has been confirmed by measuring the pulsation with a gas analyzer. The result here implies large amount of back and forth gas movement in the exhaust tube. Such amount of pulsation can cause maximum five times higher erroneous result with the pressure domain averaging when compared to a flow rate domain averaging.
\end{abstract}

Key Words: Pulsation, Oscillatory Flow, Flow Meter, Exhaust Flow Measurement, Pitot Tube

\section{1. 粕}

エンジン排ガス中の污染物質の低濃度化やパワー トレーンの複雑化にともない，従来の試験設備を用い た污染物質の排出質量計測や瞬時然費計測は非常に困 難になってきている. このような状況から，代替とな る計測手法が数多く提案されてきており，それらの手 法の中で排ガス流量の計測は重要な役割を占めるよう になってきている(い)

一方，エンジン排ガスの特徵として，（1）流体 の温度が低温から高温まで変化する，（2）流量が数 十リットル毎分から数千リットル每分まで大きく変化

* 原稿受付 2003 年 9 月 1 日.

*1 正員, (株) 堀場製作所 ( 601-8510 京都市南区吉祥院宮の 東町 2).

*2 (株) 堀場製作所.

*3 正員, 同志社大学大学院工学研究科( 610-0321 京田辺市 多々羅都谷 1-3)

E-mail : hiroshi.nakamura @ horiba.com
する，（3）流量乃瞬時に変化する，（4）流体中の 組成が大きく変動する，（5）多量の水蒸気, 粉塵を 含む，（6）流体の脈動が大きい，などがあげられ, 一般的なガス流量測定技術を用いて排ガス流量を直接 測定するのは非常に困難である.

特に, エンジン排ガスはアイドル時には逆流を含 む大きな胍動流を生じるために，逆流を計測できない ベンチュリー流量計や, オリフィス流量計, カルマン 流量計などでは正確な計測が不可能である. 本研究で は，逆流の計測が可能である排ガス流量計のひとつと し Pitot 管式流量計を採用し評価を行った. Pitot 管式 流量計は構造が単純であり, 応答も速く, 高温で水蒸 気を含む流体の測定が可能であるが，脈動流体の計測 時に大きな誤差を生じると報告されているいか．本研 究では, Pitot 管流量計の脈動流計測の検証およひ毁 差の解析を行い，胍動流を正確に計測する手法を開発 した. 
2.おもな記 号

QEX : 排ガス流量 [L/min]

$K:$ Pitot 管校正係数

$d P$ : Pitot管差圧 $[\mathrm{kPa}]$

$D_{E X}$ : 排ガス密度 $\left[\mathrm{kg}^{2} \mathrm{~m}^{3}\right]$

$P_{\mathrm{EXX}}$ : 排ガス圧力 $[\mathrm{kPa}]$

$T E x$ : 排ガス温度 [K]

$f:$ 胍動周波数 [Hz]

$N$ : エンジン回転数 $[\mathrm{ppm}]$

$M:$ エンジン気筒数

$V_{p}:$ 脈動流速の振幅 $[\mathrm{m} / \mathrm{s}]$

$V_{\text {pmax }}$ ：管断面における振幅の最大値 $[\mathrm{m} / \mathrm{s}]$

$V_{\text {pare }}$ : 管断面における振幅の平均值 $[\mathrm{m} / \mathrm{s}]$

$V_{a}:$ 胍動流速の平均流速 $[\mathrm{m} / \mathrm{s}]$

$R:$ 排気管の半径 $[\mathrm{m}]$

$R_{x}:$ 排気管の中心功の距離 $[\mathrm{m}]$

$V_{p x}: \mathrm{Rx}$ における管断面における振幅 $[\mathrm{m} / \mathrm{s}]$

\section{3. 実験装置および方法}

図1に，Pitot 管を用いた実験装置を示す．Pitot管 は内径 $30 \mathrm{~mm}$ の配管に取り付けられており, Pitot 管 自身は外径 $6 \mathrm{~mm}$ ，内径 $4 \mathrm{~mm}$ の円筒管て配管中央よ り $11 \mathrm{~mm}$ の位置に $\phi 2 \mathrm{~mm}$ の全圧孔が 2 つあるものを 使用した. また，配管壁面に $\phi 2 \mathrm{~mm}$ の静圧孔を設け， 全圧孔と静圧孔の差圧を, 外径 $6 \mathrm{~mm}$, 内径 $4 \mathrm{~mm}$, 長 さ $5 \mathrm{~m}$ の配管を通じて差圧計によって測定した. 流量 を標準状態に換算するために, 流体の温度, 絶対圧力 をそれぞれ計測した。

Pitot 管式流量計の流量演算は，Pitot 管の差圧が正 の時は式（1），差圧が負のときは式（2）を用いた. ここで，Pitot管の校正係数 K および Kの值は，正方 向および逆方向の定常流を用いて, ベンチュリー流量 計のひとつである SAO(Smooth Appmach Orifice)流量 計で校正し算出した.

$Q_{E X}=K \times \sqrt{\frac{d P}{D_{E X}} \times \frac{P_{E X}}{101.3} \times \frac{293.15}{T_{E X}}}$

$Q_{E X}=-K^{\prime} \times \sqrt{\frac{|d P|}{D_{E X}} \times \frac{P_{E X}}{101.3} \times \frac{293.15}{T_{E X}}}$

使用したエンジンは，1.6L，4 気筒のガソリンエン ジンで，アイドル状態時の排ガス胍動流量を計測した. また，アイドル状態の胍動を正確に計測するために, Pitot 管の差圧を計測する差圧計は，応答周波数が脈
動周波数よりも充分に速い $2 \mathrm{kHz}$ であるものを使用し た.

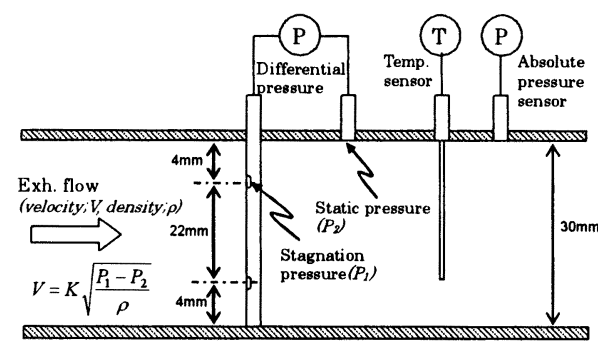

Fig. 1Schematic of Pitot tube flow meter

\section{4. 実験結果と考察}

\subsection{Pitot 管式流量計による脈動流計測}

図 2に，定常流量を Pitot 管式流量計で測定した時 に発生する Pitot 管の差圧と, SAO 流量計で測定した 基準流量との関係を示す．流量が正方向の時は Bemoulli の定理から導かれる（1）式に表したとお り, 差圧の平方根と流速が直線関係となっている.こ れに対し，逆方向の流れに対しては流体の粘性による 流れの剥離がおこるため Bernoulli の定理は適用でき ないが，剥離によって発生する負圧の平方根が流速と 直線関係になっていることがわかる. それぞれ Pitot 管の差圧の平方根が流量と直線関係になっていること が確認できたため，以下の試験にはこうして得られた Pitot管校正係数を用いて評価を行った.

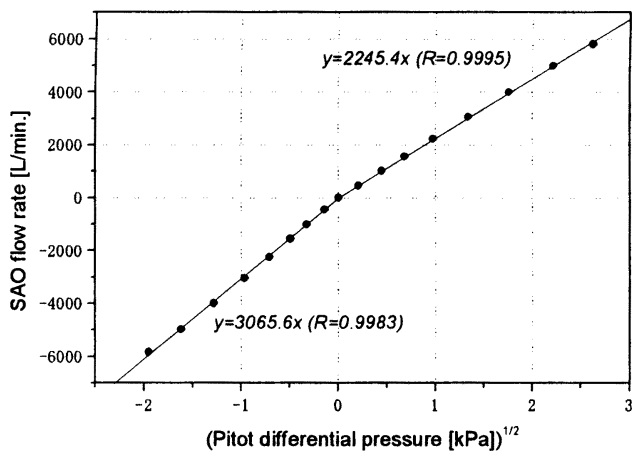

Fig.2 Calibration result of Pitot flow meter 


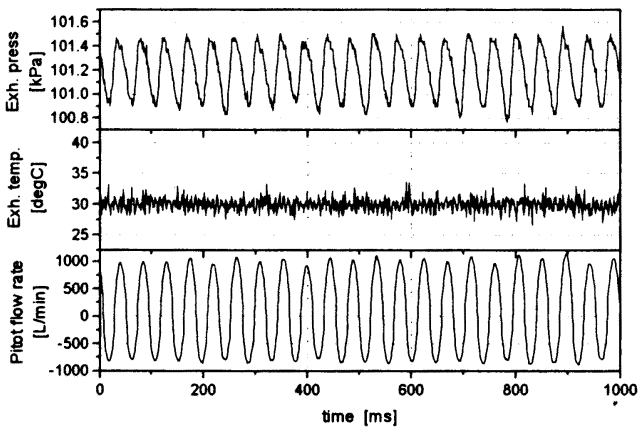

Fig. 3 Exhaust flow at idling measured by Pitot flow meter.

図 3に, Pitot 管式流量計によって, エンジン回転 650 mm のアイドル状態での排ガス流量を測定した結 果を示す. 排ガス圧力およひ排ガス流量ともに正弦波 に近似した出力が得られており，また試験中における エンジン回転数から式 (3) より計算した脈動周波数 $21.7[\mathrm{~Hz}]$ と同等の周波数が検出されている.

$$
f=\frac{1}{2} \times N \times \frac{1}{60} \times M
$$

また，Pitot 管によって測定した脈動流量は平均流 量が約 70 [L/minlであるのに対し，振幅は， \pm 900 【L/min]にもなっていることが観測された。

\section{2 エンジン眽勀流の保析}

図 4に，Pitot 管式流量計によって観測された逆流 を含むエンジン胍動流量が妥当であるかを確認するた めに使用した装置を示す．使用したエンジンはガソリ ンエンジンであり，理論空然比( $(\lambda=1)$ に制御されてい るために排ガス中の $\mathrm{O}_{2}$ 浱度はほぼゼロであるが，脈 動によって逆流を生じている時には，大気中の $\mathrm{O}_{2}$ を 排気管から吸い込み，排気管出口からある距離までは $\mathrm{O}_{2}$ が逆流しているはずである.この逆流の距離しを ジルコニア式 $\mathrm{O}_{2}$ 計によって測定した.

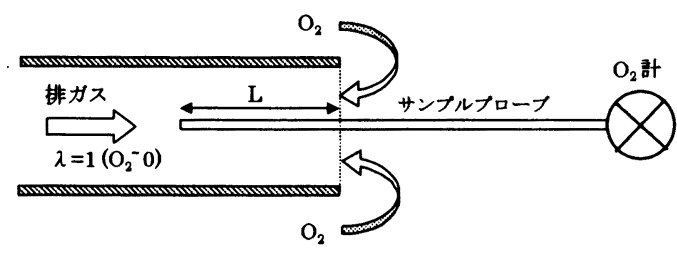

Fig 4 Schematic of backwand flow evaluation test.

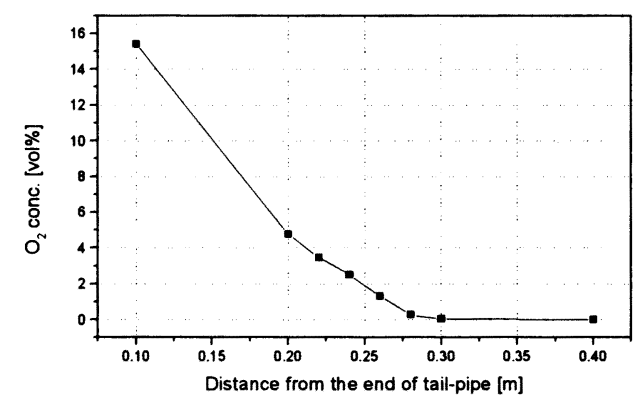

Fig. 5 Distance of backward flow penetration in engine exhaust tailpipe.

図 5 に，排気管出口からの距離における $\mathrm{O}_{2}$ 濃度を 示す.この結果から，逆流による排ガスの逆方向への 移動距離は, 本実験条件において約 $0.3[\mathrm{~m}]$ であるこ とがわかる. 図6に，理想的なエンジン胍動波形にお ける脈動振幅のモデルを示す.ここで， $V_{p}$ は脈動速 度の振幅, $V_{a}$ は脈動流の平均速度を表している. 逆 流距離の計測と本モデルを用いて， $V_{p}$ 算出する.

このとき，逆流による移動距離は，逆流速度を脈 動周期の半周期分積分することによって式 (4) のよ うに表される.

$$
L=\int_{0}^{T / 2}\left(V_{p} \sin (\omega t)-V_{a}\right) d t
$$

(4)

$$
=\frac{1}{f}\left(\frac{V_{p}}{\pi}-\frac{V_{a}}{2}\right)
$$

よって, 脈動速度の振幅は, 式（5）で表される.

$$
V_{p}=\pi\left(L f+\frac{V_{a}}{2}\right)
$$

試験結果から逆流による移動距離は $L=0.3[\mathrm{ml}$, 脈 動周波数 $f 21.7[\mathrm{~Hz}]$, 平均流速は，別報により報告し ている $\mathrm{OO}_{2}$ トレース法によって測定したアイドル時 の平均流量 $(70 \mathrm{~L} / \mathrm{min})$ より $V_{a}=1.285[\mathrm{~m} / \mathrm{s}]$ として計算す ると $V_{p}=225[\mathrm{~m} / \mathrm{s}]$ となる. ここで, 図 4 に示したよ うに，逆流によって吸い込まれる $\mathrm{O}_{2}$ の移動距離は， 配管のほぼ中央で測定したために上記の $V_{p}$ 値は，配 管中の流速分布における振幅の最大速度 $V_{\text {pmax }}$ である とええられる.これに対し，Pitot 管式流量計では平 均流量を計測しているために, 振幅の平均速度 $V_{\text {pare }}$ を見積もった。 
乱流のときの円筒管内の流速分布は指数法則の式 （6）によって表される. この式を円筒管の全断面に わたって積分し，これを円筒管の断面積で割ることに より平均速度と最大速度の関係は式（7）で表される. ()

$\frac{V_{p x}}{V_{p \max }}=\left(1-\frac{r_{x}}{R}\right)^{1 / n}$

(6)

$V_{p a v e}=\frac{2 n^{2}}{(n+1)(2 n+1)} V_{p \max }$

(7)

ここで $n$ は Re 数の関数で表される値であり, 流速 が $22[\mathrm{~m} / \mathrm{s}]$ ときの圾験排気管におけるレイノルズ数

（Re数）は約 44900 であり，この時 $\mathrm{n}=68$ とすると 9 , 胍動速度の振幅は $V_{\text {pare }}=18.46[\mathrm{~m} / \mathrm{s}]$ と計算できる.

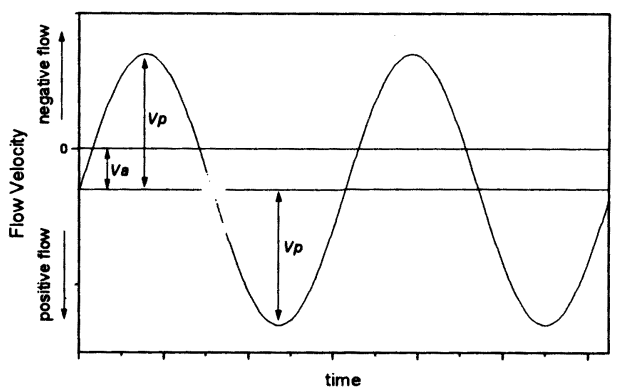

Fig. 6 A modeled flow rate with strong pulsation as a function of time.

図 7 に，Pitot 管式流量計によって測定したエンジ ン胍動流の波形と, 上記の計算によって得た振幅の平 均速度 $V_{\text {paw }}$ およひ胍動流の平均速度 $V_{a}$ によって算出 したエンジン胍動波形のモデルとを比較した結果を示 す. ここで, 比較のため胍動波形のモデルは配管の断 面積を乗じることにより流量に換算している. それぞ れの胍動の振幅はほぼ一致しているため, Pitot 管式 流量計のエンジン胍動流量の測定結果は, 脈動の計測 として妥当なふるまいであることが判断できる.

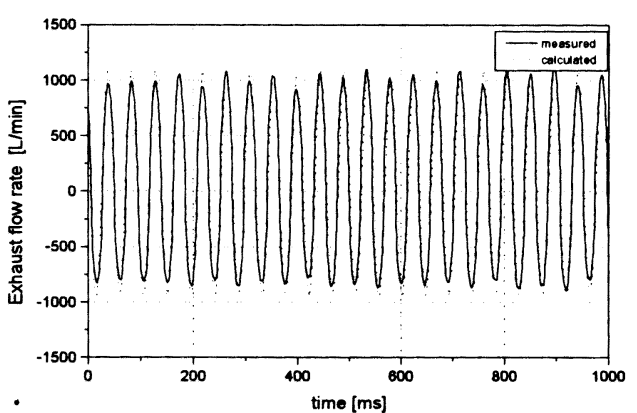

Fig 7 Comparison of pulsation flow between the Pitot tube measurement and the calculation from backward flow penetration.

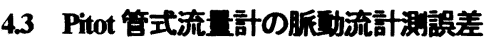

Pitot 管式流量計やベンチュリー流量計は，差圧を 流量に換算する際に差圧の平方根をとるため, 差圧と 流量は非直線関係にある. 図8に, 差圧の計測値と算 出される流量の関係, およひ胍動計測時の誤差メカニ ズムを示す．図から分かるように，エンジン排ガスの 様に胍動が大きい流量を測定する場合，胍動による差 圧の平均を流量に換算すると，胍動流自身の平均值よ りも高めの測定誤差を生じることになる. 実際に，エ ンジン排ガスを Pitot 管式流量計によって測定すると アイドル状態で約 3〜 6倍の測定誤差が生じる場合が あると報告されている心(か)。

この差圧の平均化による誤差が流量に与える影響 を確認するために，2kHz の応答周波数を持つ差圧計 で測定した差圧波形を 1 次の低域通過フィル夕に通し， 任意に応答周波数を遅くした差圧波形を流量に換算す るときに生じる測定誤差を検証した.

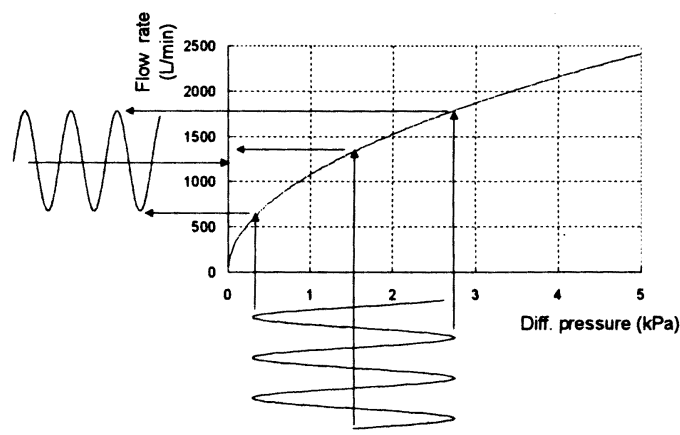

Fig. 8 Relation between differential pressure of Pitot tube and averaging error mechanism. 
図 9 に, $2 \mathrm{kHz}$ の応答周波数の差圧計によって測定 した Pitot 管の差圧と流量, および応答周波数を $1.6 \mathrm{~Hz}$ にしたときの差圧と流量の波形を示す．差圧波 形は応答が遅くなることにより振幅が减少し平均化さ れた波形となっているのに対し，それを流量に換算す ると, 流量の振幅が減少しているのと同時に, 平均流 量が高めにオフセットしていることが確認できる.

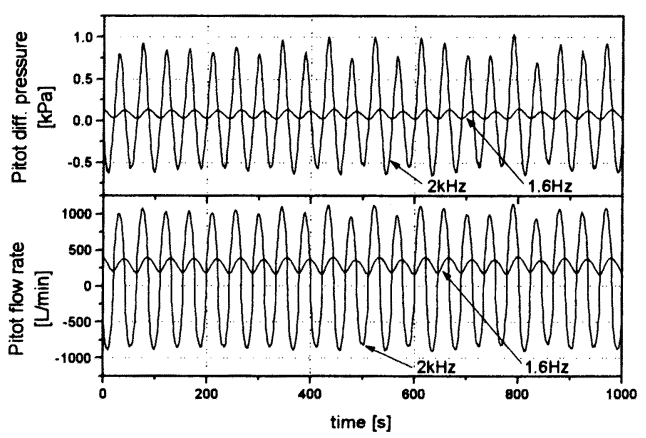

Fig. 9 Averaging emar of Pitot flow meter

図 10 に, $2 \mathrm{kHz}$ の応答周波数を持つ差圧計で測定 した差圧波形を 1 次の低域通過フィルタに通し、遮断 周波数を $2 \mathrm{kHz}$ から $0.2 \mathrm{~Hz}$ まで変化させたときの差圧 波形より計算した平均流量值を示寸.アイドル時の脈 動周波数である約 $20 \mathrm{~Hz}$ 以下の応答周波数で測定誤差 が極端に大きくなっており, 応答周波数が $0.2 \mathrm{~Hz}$ では その測定值は実流量の平均值の約 5 倍にもなっている ことが確認できる. また，この試験結果ではアイドル 時の胍動周波数である $20 \mathrm{~Hz}$ の応答周波数の測定系を 用いた場合でも約 $30 \%$ の測定誤差を生じている.こ の測定誤差は，脈動流体の平均流量およびその振幅に よって変化するが, 本試験で用いたような一般的な小 型ガソリンエンジンより発生する脈動流体（平均流量 が約 70L/min，振幅が約 $900 \mathrm{~L} / \mathrm{min}$ ）を $5 \%$ 以内の測定 誤差にするためには稚動周波数の 5 倍以上の応答周波 数を持つ測定系 (Pitot 管から差圧計までの導圧管を 含む全測定系）が必要であることがわかる.

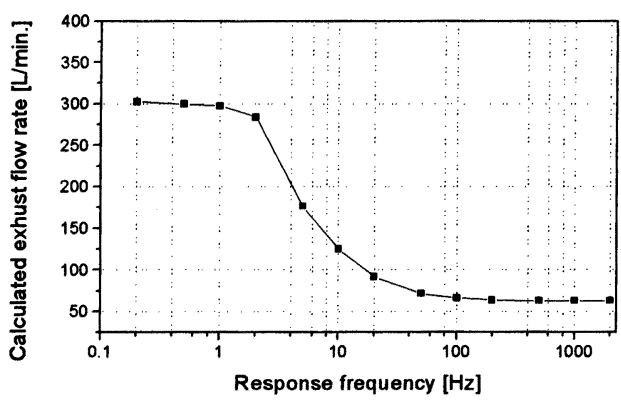

Fig. 10 Influence of frequency response of differential pressure sensor on Pitot averaging error.

\section{5. 結論}

（1）Pitot 管式流量計を用いて逆流を含むエンジン 排ガスの脈動流量を計測するのに成功した.

（2）1.6L のガソリンエンジンの排ガスにおいて, アイドルの時の平均流量が約 70 [L/min] である のに対し，胍動流の振幅は土900[L/min]にもな っていることが観測された。

（3）本圾験で用いたような一般的なエンジンより発 生する脈動流体（脈動周波数が約 $20 \mathrm{~Hz}$ ，平均 流量が約 $70 \mathrm{~L} / \mathrm{min}$ ，振幅が約 $\pm 900 \mathrm{~L} / \mathrm{min}$ ）を応 答周波数が約 $0.2 \mathrm{~Hz}$ の測定系をもつ Pitot管式流 量計で測定した場合，平均化による誤差は 500\%にもなることが確認できた.

（4）Pitot 管式流量計を用いてエンジン排ガス流量 を測定する場合には，想定される脈動周波数よ りも充分に応答の速い差圧計と組み合わせる必 要がある.

\section{文献}

(1) D. B. Nagy, J. Loo, J Tulpa, P. Schroeder, R. Middleton, SAE paper 2000-01-0793.

(2) D. J. Luzenski, K. T. Bedsole, J. Hill, D. B. Nagy, S. S. Decarteret, SAEpaper2002-01-0047.

(3) K. Inoue, M. Ishihara, K. Akashi, M. Adachi, K. Ishida, SAE paper 1999-01-0150.

(4) M. Guenther, M. T. Sherman, M. Vaillanoourt, D. Carpenter, R. Rooney, S. Porter, SAEpaper2002-01-0046.

(5) M. Guenther, T.Henney, W. M. Silvis, S. Nakatani, D. Y.Wu, SAEpaper2000-01-0792.

（6）成瀬由希夫，依田公一，公開特許公報，特開平 10-318810。 
(7) H. Nakamura, N. Kihara, M. Adachi, K. Ishida, SAEpaper 2002-01-0612

(8) H. Nakamura, N. Kihara, M. Adachi, S. Nakamura, K. Ishida, JSAEReview 24(2003), 127·133.
（9）松山裕, 実用流量測定, (1995), 181, 財団法人省エネルギーセ ンター

(10) W. Silvis, J. Williamson, N. Kreft, A. Alajbegovic, SAEpaper 2003-01-0782 